\title{
Investigation of the Effect of Sociodemographic and Occupational Factors on Fatigue, Organizational Commitment and Job Satisfaction among Employees in the Pharmaceutical Industry
}

\author{
Paraskevi Theofilou ${ }^{1,2 *}$, Sofia Zyga ${ }^{1}$, Charalampos Economou ${ }^{3}$, Foteini Tzavella1 \\ ${ }^{1}$ Department of Nursing, University of Peloponnese, Tripoli, Greece \\ ${ }^{2}$ Ministry of Health, General Direction of Health Services, Athens, Greece \\ ${ }^{3}$ Department of Sociology, Panteion University of Social and Political Sciences, Athens, Greece \\ Email: * pardrothe@gmail.com
}

How to cite this paper: Theofilou, P., Zyga, S., Economou, C., \& Tzavella, F. (2021). Investigation of the Effect of Sociodemographic and Occupational Factors on Fatigue, Organizational Commitment and Job Satisfaction among Employees in the Pharmaceutical Industry. Open Journal of Social Sciences, 9, 173-187.

https://doi.org/10.4236/jss.2021.94014

Received: March 22, 2021

Accepted: April 17, 2021

Published: April 20, 2021

Copyright $\odot 2021$ by author(s) and Scientific Research Publishing Inc. This work is licensed under the Creative Commons Attribution International License (CC BY 4.0).

http://creativecommons.org/licenses/by/4.0/

\begin{abstract}
Working conditions in modern times are a key factor related to organizational commitment, job satisfaction and fatigue among employees in pharmaceutical companies. The aim of this study was to explore the effect of socio-demographic and work factors on the levels of fatigue, organizational commitment and job satisfaction in employees of pharmaceutical companies. Participants of varied sectors $(\mathrm{N}=102)$ completed the Fatigue Assessment Scale (FAS), the Meyer and Allen Organizational Commitment Questionnaire as well as the Employee Satisfaction Inventory (ESI). The results showed that factors such as age, holding or not a position of responsibility, education, marital status, staff specialization, working hours per week, the total working experience as well as the years of work in the department in which the employees are now occupied, have a statistically significant effect on fatigue, organizational commitment and job satisfaction. In conclusion, it seems that there is an effect of various socio-demographic and work factors on the variables under investigation.
\end{abstract}

\section{Keywords}

Fatigue, Organizational Commitment, Job Satisfaction, Pharmaceutical Industry

\section{Introduction}

In recent years, there has been intense research interest from health scientists 
regarding fatigue and the effects it may bring as it is not uncommon in the healthy population (Fritschi \& Quinn, 2010). Specifically, fatigue is a subjective experience and therefore there is difficulty in identifying and detecting it accurately. In fact, it is a complex of biological, psychological and social processes, which is characterized by a decrease in the ability to work and efficiency of the individual (Alikari et al., 2016). Usually, the different meanings of fatigue incorporate at least two fundamental factors: duration and severity, while its dimensions are often distinguished in physical fatigue and mental fatigue.

Physical fatigue is characterized by difficulties and reduced ability to perform physical work due to previous physical exercise (Gawron, French \& Funke, 2001). As a result, physical fatigue can lead to reduced endurance, reduced movement control and general discomfort. These effects in turn lead to reduced productivity, negatively affect the quality of work and reduce performance in the workplace (Côté et al., 2005; Huysmans et al., 2010). Mental fatigue reflects reduced cognitive abilities and less willingness to act according to the requirements of the project due to previous physical or mental effort (Meijman, 1997). In other words, fatigue is generally associated with persistent and significant exhaustion, physical or mental, or both.

On the other hand, organizational commitment and job satisfaction were two of the recurring conceptual constructs in the scientific literature on job organization. Traditionally, they have been associated with the desired and undesirable behavior of those who interact within an organizational system. Therefore, the ongoing view is that both of these variables are correlated, as the most immediate positive emotions, such as satisfaction, evoke a more and more collaborative attitude, such as organizational commitment.

In a study of organizational commitment, Meyer et al. (1993) have defined three types of it: affective, normative and continuance. Affective commitment is the emotional attachment and identification of employees with their organization. Normative commitment is the sense of obligation of employees to remain in the organization, while continuance commitment implies the cost of leaving the organization. Several studies have highlighted the relationship between employee fatigue, decreased satisfaction and reduced organizational commitment (Maslach, Schaufeli \& Leiter, 2001; Ariapooran, 2014; Fradelos et al., 2014) and therefore a shift in academia has been observed to investigate and pinpoint the factors that affect this relationship.

In particular, Marchese and Ryan (2001) found that full-time employees had a higher level of efficiency, higher satisfaction and organizational commitment than part-time employees. A series of similar studies (McGinnis \& Morrow, 1990; Thorsteinson, 2003; Clinebell \& Clinebell, 2007; Al Omar et al., 2011) which investigate differences in job satisfaction between full-time and part-time workers have shown that no significant differences are observed. However, there is a difference in job commitment and this may be due to the fact that part-time employment is often an additional job and source of income, while employees have 
other main professional obligations, to which they are more committed (Thorsteinson, 2003).

In the research of Anis, Khan and Humayoun (2011) related to pharmaceutical companies in Pakistan, the relationship between employee retention, perceived support by supervisors, compensation, job satisfaction and organizational commitment was studied. Their results underlined the positive relationship between supervisory support, compensation and organizational commitment, but also the positive relationship between organizational commitment, job satisfaction and willingness to stay in the same workplace. Another study found that job demands were associated with more emotional exhaustion, more depersonalization and less personal achievement, while support from supervisors and growth opportunities were associated with less emotional exhaustion and higher levels of personal fulfillment (Woodhead, Northrop, \& Edelstein 2016).

Additionally, through Harkin and Melby's (2014) research into emergency department nurses and clinical nurses, work-related factors, gender, age, marital status, and the number of hours worked per week were significant in terms of their association with occupational fatigue. On the other hand, a recent study on fatigue in female nurses showed that they had high rates of fatigue, while it appeared that work fatigue was affected by their employment status, age, husband support and work experience, but not by their marital status, official position, work shift, having a suckling or having a second job (Pourmovahed \& Nasiriani, 2016).

Summarizing the literature, it has been shown that some of the factors that determine the relationship between fatigue, organizational commitment and job satisfaction are work schedules and shifts (Han, Trinkoff, \& Geiger-Brown, 2014), mentally and/or physically challenging tasks (Barker \& Nussbaum, 2011; Pourmovahed \& Nasiriani, 2016), work-family conflicts (Bakker, Demerouti, \& Dollard, 2008; Ilies et al., 2015), stress (Stokes \& Kite, 2017), low salary (Tang et al., 2019), social support (Ariapooran, 2014), equipment, quality condition of buildings, staffing with human resources and logistics infrastructure of workplaces (Fagermoen, 1997; Forrest, 1989; Tang et al., 2019). The association of sociodemographic as well as organizational factors with job satisfaction has been also indicated in other studies (Buker \& Dolu, 2010; Sarminah, 2006).

Research associated with fatigue, organizational commitment, job satisfaction has been carried out on various workgroups (Cordes \& Dougherty, 1993; Maslach et al., 2001; Oh, Sung, \& Kim, 2011; Ali \& Kakakhel, 2013). Nevertheless, the number of surveys conducted in Greece and those particularly that concern employees' demographics are insufficient. Therefore, the purpose of the current study was to investigate the effect of socio-demographic and work factors on levels of fatigue, organizational commitment and job satisfaction among employees in pharmaceutical companies. The main research hypothesis was that there will be a statistically significant effect of socio-demographic and occupational factors on the levels of the above variables in the population un- 
der study.

\section{Method}

\section{Research Design and Sample}

The variables examined in this quantitative cross-sectional study were the rates of fatigue, organizational commitment and job satisfaction of employees in pharmaceutical companies. The present research involved personnel of different specialties (e.g. medical visitors, administrative staff, laboratory staff, managers etc.) working in Athens. For the selection of the sample were set as admission criteria people to be over 18 years old, to work at least one year in this field and to know the Greek language fluently. The presence of any psychiatric disorder was the only exclusion criterion.

\section{Questionnaires}

Initially, participants filled out a form with their demographic and professional details. Participants then completed the "The Fatigue Assessment Scale (FAS)", which is a tool for assessing perceived fatigue and consists of 10 questions on a five-point Likert scale $(1=$ never to $5=$ always), with a score of ranges between 10 - 50. Five questions are about physical and five questions are about mental fatigue. This scale is considered a reliable tool for measuring fatigue for both healthy people and people with diseases (Michielsen et al., 2003; Michielsen et al., 2004; Zyga et al., 2015).

Respondents also completed the Organizational Commitment Questionnaire, which includes 18 statements based on the three-dimensional model of organizational commitment, according to Meyer, Allen and Smith (1993). This tool evaluates both organizational commitment and its three dimensions (affective, continuance, normative). For each dimension the tool includes 6 statements. The employee responds using the Likert 5-point scale (Allen \& Meyer, 1990).

The Employee Satisfaction Inventory-ESI (Koustelios \& Bagiatis, 1997) was used to measure job satisfaction. This questionnaire was chosen because it explores all the dimensions that compose the concept of staff satisfaction, but also because its validity and reliability have been examined in similar surveys in Greece (Koustelios \& Bagiatis, 1997; Koustelios \& Kousteliou, 1998). The recording scale consists of a total of 24 items and has the following six subscales: Working Conditions, Salary, Nature of Work, Direct Supervisor, Organization as a whole and Promotion. To answer whether respondents considered each ability important, they used a five-point scale $(1=$ strongly disagree to $5=$ strongly agree).

\section{Procedure}

The researchers turned to various pharmaceutical companies to participate in the research. Questionnaires were distributed to all those who showed interest and wanted to participate. All participants in the survey were informed in detail about the purpose of the survey through the consent form they were asked to sign. In this form there was also a clear description of their right to withdraw 
data. The anonymity of the participants was ensured, as well as the confidentiality of the data. Completion of the questionnaires took approximately $10-15$ minutes.

\section{Statistical analysis}

The socio-demographic profile of the sample was presented and in particular the quantitative variables were described with mean and standard deviation ( $M$ $\pm \mathrm{SD}$ ) and the categorical variables with frequencies and percentages. Spearman correlation, Krustal-Wallis test and Mann-Whitney analysis were performed to investigate the relationship among fatigue, organizational commitment, job satisfaction and socio-demographic and occupational factors. All questionnaires demonstrated very good reliability (Cronbach a), that is 0.896 for the fatigue questionnaire, 0.814 for the organizational commitment questionnaire and 0.781 for the job satisfaction questionnaire. The value $p<0.05$ was considered to indicate statistical significance.

\section{Results}

\section{Sample characteristics}

In the present study the total sample consisted of 102 people, of whom $52.9 \%$ were men and $47.1 \%$ women. The majority was university graduates (58.8\%), married or with a cohabitation agreement (58.8\%), medical visitors (35.3\%) and having a position of responsibility (61.8\%) (Table 1).

The mean age of the study participants was 43.3 years $( \pm 7.66)$. The average total working hours was $13 \pm 7.8$, the average working hours in the department was $8.17 \pm 6.54$ and the average weekly working hours was $38.5 \pm 14.3$.

Also, $52.9 \%$ of the sample did not have fatigue, while $47.1 \%$ did. The mean of physical fatigue was $11.6 \pm 3.3$, of mental fatigue was $8.97 \pm 2.65$ and the mean of total fatigue was $20.6 \pm 5.4$. The mean of affective commitment was $20.7 \pm 4.8$, continuance commitment was $18.9 \pm 4.6$, normative commitment was $17.7 \pm 4.7$ and total commitment was $57.3 \pm 10.9$. The average satisfaction with the working conditions was $18.9 \pm 3.9$, the satisfaction with the salary $12.4 \pm 3.3$, the satisfaction with the promotion $9.3 \pm 2.3$, the satisfaction with the nature of the work $15.7 \pm 3$, by the immediate supervisor $15.1 \pm 4.1$ and the satisfaction from the organization $13.1 \pm 3.7$.

\section{Main results}

According to Table 2, there were statistically significant differences between the two genders with women showing higher levels of satisfaction compared to men in terms of working conditions $(M=58.06, p=0.033)$ and promotion $(M=$ 60.31, $p=0.004)$.

Moreover, statistically significant differences were observed (Table 3) between individuals with or without a position of responsibility, with those who did not have a position of responsibility exhibiting higher levels of physical $(M=52.91$, $p=0.003)$ and total fatigue $(M=60.62, p=0.014)$. In addition, those in positions of responsibility showed higher rates of affective $(M=59.43, p=0.001)$ 
Table 1. Demographics and other characteristics of the participants.

\begin{tabular}{|c|c|c|}
\hline & $\mathbf{N}$ & $\%$ \\
\hline \multicolumn{3}{|l|}{ gender } \\
\hline men & 54 & 52.9 \\
\hline women & 48 & 47.1 \\
\hline \multicolumn{3}{|l|}{ education } \\
\hline lyceum & 9 & 8.8 \\
\hline University & 60 & 58.8 \\
\hline postgraduate/doctoral & 33 & 32.4 \\
\hline \multicolumn{3}{|l|}{ marital status } \\
\hline unmarried & 33 & 32.4 \\
\hline married-cohabitation agreement & 60 & 58.8 \\
\hline divorced & 6 & 5.9 \\
\hline widowed & 3 & 2.9 \\
\hline \multicolumn{3}{|l|}{ specialty } \\
\hline research/laboratory staff & 15 & 14.7 \\
\hline medical visitors & 36 & 35.3 \\
\hline administrative staff & 18 & 17.6 \\
\hline senior executives (managers) & 33 & 32.4 \\
\hline \multicolumn{3}{|l|}{ position of responsibility } \\
\hline yes & 63 & 61.8 \\
\hline no & 39 & 38.2 \\
\hline
\end{tabular}

Table 2. Gender differences in fatigue, organizational commitment and job satisfaction

\begin{tabular}{ccccc}
\hline & Male & Female & \multirow{2}{*}{$\boldsymbol{P}$} \\
\cline { 1 - 2 } Physical Fatigue & \multicolumn{2}{c}{$\boldsymbol{M}$} & \\
Mental Fatigue & 50.25 & 52.91 & 0.649 \\
Total Fatigue & 50.25 & 52.91 & 0.645 \\
Affective Commitment & 50.42 & 52.72 & 0.694 \\
Continuance Commitment & 49.17 & 54.13 & 0.396 \\
Normative Commitment & 56.75 & 45.59 & 0.056 \\
Total Commitment & 52.00 & 50.94 & 0.856 \\
Working Conditions Satisfaction & 50.42 & 52.72 & 0.694 \\
Salary Satisfaction & 45.67 & 58.06 & 0.033 \\
Promotion Satisfaction & 50.50 & 52.63 & 0.715 \\
Nature of Work Satisfaction & 43.67 & 60.31 & 0.004 \\
Direct Supervision Satisfaction & 50.50 & 52.63 & 0.715 \\
Organization Satisfaction & 51.25 & 51.78 & 0.927 \\
\hline & 49.25 & 54.03 & 0.412 \\
\hline
\end{tabular}


Table 3. Differences between having or not a position of responsibility in terms of fatigue, organizational commitment and job satisfaction

\begin{tabular}{cccc}
\hline & \multicolumn{2}{c}{ Position of Responsibility } & \\
\cline { 2 - 3 } & Yes & No & \\
\cline { 2 - 3 } & \multicolumn{2}{c}{$\boldsymbol{M}$} & \\
\hline Physical Fatigue & 44.71 & 62.46 & 0.003 \\
Mental Fatigue & 48.43 & 56.46 & 0.175 \\
Total Fatigue & 45.86 & 60.62 & 0.014 \\
Affective Commitment & 59.43 & 38.69 & 0.001 \\
Continuance Commitment & 48.36 & 56.58 & 0.171 \\
Normative Commitment & 54.29 & 47.00 & 0.225 \\
Total Commitment & 57.14 & 42.38 & 0.014 \\
Working Conditions Satisfaction & 54.36 & 46.88 & 0.212 \\
Salary Satisfaction & 49.07 & 55.42 & 0.288 \\
Promotion Satisfaction & 60.21 & 37.42 & 0.000 \\
Nature of Work Satisfaction & 53.14 & 48.85 & 0.472 \\
Direct Supervision Satisfaction & 56.36 & 43.65 & 0.033 \\
Organization Satisfaction & 53.71 & 47.92 & 0.334 \\
\hline
\end{tabular}

and total commitment $(M=57.14, p=0.014)$ as well as satisfaction with promotion $(M=60.21, p<0.001)$ and their immediate superior $(M=56.36, p=0.033)$.

As it can be seen from Table 4, there were statistically significant differences between individuals with different educational level. In particular, high school graduates showed higher scores in terms of physical $(M=88.00, p<0.001)$, mental $(M=73.50, p=0.042)$ and total fatigue $(M=84.50, p<0.001)$. Also, they presented greater continuance commitment $(M=70.00, p=0.007)$, while bachelor holders scored higher in terms of satisfaction from the immediate supervisor $(M=54.05, p=0.036)$. It should also be noted that there was a tendency for a statistically significant difference between people with different educational levels in terms of affective commitment $(M=56.55, p=0.050)$ and salary satisfaction $(M=57.09, p=0.049)$ with holders of postgraduate or doctoral degree to show a higher score compared to the other groups.

Statistically significant differences occurred between individuals with different marital status (Table 5). Specifically, the divorced displayed higher rates of physical fatigue $(M=62.00, p=0.019)$, while the single ones showed higher rates of total fatigue $(M=61.86, p=0.020)$. Regarding the commitment, the married or with civil partnership indicated a higher continuance commitment $(M=58.63, p$ $=0.015)$, and the divorced showed a higher normative $(\mathrm{M}=86.75, p=0.012)$ and total commitment $(M=75.50, p=0.007)$.

On the other hand, in terms of satisfaction (Table 5), widowed were more satisfied with working conditions $(M=68.00, p=0.006)$, salary $(M=83.00, p=$ 
Table 4. Differences between educational levels in terms of fatigue, organizational commitment and job satisfaction.

\begin{tabular}{ccccc}
\hline & \multicolumn{3}{c}{ Education } & \\
\cline { 2 - 4 } & $\begin{array}{c}\text { High School } \\
(\mathbf{N}=9)\end{array}$ & $\begin{array}{c}\text { Bachelor } \\
(\mathbf{N}=60)\end{array}$ & $\begin{array}{c}\text { Master/PhD } \\
(\mathbf{N}=33)\end{array}$ & $p$ \\
\cline { 2 - 4 } & & $\boldsymbol{M}$ & \\
Physical Fatigue & 88.00 & 48.88 & 46.32 & 0.000 \\
Mental Fatigue & 73.50 & 47.53 & 52.73 & 0.042 \\
Total Fatigue & 84.50 & 47.83 & 49.18 & 0.002 \\
Affective Commitment & 29.50 & 52.03 & 56.55 & 0.050 \\
Continuance Commitment & 70.00 & 55.25 & 39.64 & 0.007 \\
Normative Commitment & 44.00 & 53.00 & 50.82 & 0.685 \\
Total Commitment & 40.00 & 54.35 & 49.45 & 0.353 \\
Working Conditions Satisfaction & 38.00 & 53.45 & 51.64 & 0.339 \\
Salary Satisfaction & 30.00 & 51.65 & 57.09 & 0.049 \\
Promotion Satisfaction & 48.50 & 46.93 & 60.64 & 0.092 \\
Nature of Work Satisfaction & 32.00 & 55.85 & 48.91 & 0.062 \\
Direct Supervision Satisfaction & 27.50 & 54.05 & 53.41 & 0.036 \\
Organization Satisfaction & 42.50 & 53.15 & 50.95 & 0.593 \\
\hline
\end{tabular}

Table 5. Differences in marital status in terms of fatigue, organizational commitment and job satisfaction.

\begin{tabular}{cccccc}
\hline & \multicolumn{5}{c}{ Marital Status } \\
\cline { 2 - 5 } & $\begin{array}{c}\text { Single } \\
(\mathbf{N}=33)\end{array}$ & $\begin{array}{c}\text { Married/Civil } \\
\text { Partnership } \\
(\mathbf{N}=60)\end{array}$ & $\begin{array}{c}\text { Windowed } \\
(\mathbf{N}=3)\end{array}$ & $\begin{array}{c}\text { Divorced } \\
(\mathbf{N}=6)\end{array}$ & $\boldsymbol{P}$ \\
\cline { 2 - 5 } & \multicolumn{5}{c}{$\boldsymbol{M}$} \\
Physical Fatigue & 61.45 & 46.63 & 18.50 & 62.00 & 0.019 \\
Mental Fatigue & 59.55 & 49.33 & 21.50 & 44.00 & 0.092 \\
Total Fatigue & 61.86 & 47.30 & 15.50 & 54.50 & 0.020 \\
Affective Commitment & 41.55 & 56.00 & 68.00 & 53.00 & 0.106 \\
Continuance Commitment & 38.68 & 58.63 & 39.50 & 56.75 & 0.015 \\
Normative Commitment & 45.23 & 52.18 & 36.50 & 86.75 & 0.012 \\
Total Commitment & 38.95 & 56.53 & 41.00 & 75.50 & 0.007 \\
Working Conditions Satisfaction & 37.05 & 58.40 & 68.00 & 53.75 & 0.006 \\
Salary Satisfaction & 42.50 & 56.53 & 83.00 & 35.00 & 0.017 \\
Promotion Satisfaction & 51.23 & 53.83 & 42.50 & 34.25 & 0.432 \\
Nature of Work Satisfaction & 32.41 & 62.83 & 50.00 & 44.00 & 0.000 \\
Direct Supervision Satisfaction & 34.59 & 58.63 & 38.00 & 80.00 & 0.000 \\
Organization Satisfaction & 37.18 & 57.73 & 80.00 & 53.75 & 0.004 \\
\hline
\end{tabular}


$0.017)$ and with the organization $(M=80.00, p=0.004)$. Married or with civil partnership exhibited greater satisfaction from the nature of work $(M=62.83, p$ $<0.001)$, while divorced showed a higher score of satisfaction from the immediate superior $(M=80.00, p<0.001)$.

According to Table 6, there were statistically significant differences between individuals with different specialties. The laboratory/research staff displayed higher percentages of physical $(M=70.10, p<0.001)$, mental $(M=66.80, p=$ $0.046)$ and total fatigue $(M=69.80, p=0.001)$. The senior executives showed the highest affective $(M=68.00, p<0.001)$ and total commitment $(M=62.55, p=$ $0.007)$. In relation to the level of satisfaction, the senior executives disclosed the highest satisfaction from the working conditions $(M=64.59, p<0.001)$, the factor of promotion $(M=68.82, p=0.001)$, the nature of the work $(M=74.27, p<$ $0.001)$, the immediate supervisor $(M=62.68, p=0.034)$ and the organization in general $(M=58.86, p<0.001)$.

Based on the correlation analysis, there was a positive correlation of age with continuance commitment $(r=0.239, p=0.015)$, with satisfaction from the nature of the work $(r=0.273, \mathrm{p}=0.005)$ and from the immediate supervisor $(r=$ 0.197, $p=0.047)$. There was also a negative correlation of working hours per week with physical fatigue $(r=-0.197, p=0.047)$, continuance commitment $(\mathrm{r}=$ $-0.327, p<0.001)$ and satisfaction from the organization $(r=-0.196, p=0.049)$.

Table 6. Differences in sectors in terms of fatigue, organizational commitment and job satisfaction.

\begin{tabular}{|c|c|c|c|c|c|}
\hline & \multicolumn{4}{|c|}{ Sector } & \multirow{3}{*}{$p$} \\
\hline & $\begin{array}{c}\text { Research/ } \\
\text { Laboratory } \\
\text { Staff (N = } \\
15)\end{array}$ & $\begin{array}{l}\text { Medical } \\
\text { Visitors } \\
(\mathrm{N}=36)\end{array}$ & $\begin{array}{c}\text { Administrativ } \\
\text { e } \\
\text { Staff } \\
(\mathrm{N}=18)\end{array}$ & $\begin{array}{c}\text { Senior } \\
\text { executives } \\
(\mathrm{N}=33)\end{array}$ & \\
\hline & \multicolumn{4}{|c|}{$M$} & \\
\hline Physical Fatigue & 70.10 & 60.13 & 53.50 & 32.55 & 0.000 \\
\hline Mental Fatigue & 66.80 & 53.13 & 53.25 & 41.82 & 0.046 \\
\hline Total Fatigue & 69.80 & 57.38 & 52.25 & 36.36 & 0.001 \\
\hline Affective Commitment & 33.20 & 50.00 & 39.50 & 68.00 & 0.000 \\
\hline Continuance Commitment & 43.70 & 54.38 & 53.00 & 51.09 & 0.694 \\
\hline Normative Commitment & 39.50 & 51.38 & 50.50 & 57.64 & 0.268 \\
\hline Total Commitment & 30.80 & 50.38 & 50.75 & 62.55 & 0.007 \\
\hline Working Conditions Satisfaction & 21.20 & 50.25 & 55.25 & 64.59 & 0.000 \\
\hline Salary Satisfaction & 43.70 & 58.50 & 43.50 & 51.77 & 0.217 \\
\hline Promotion Satisfaction & 39.80 & 44.13 & 44.25 & 68.82 & 0.001 \\
\hline Nature of Work Satisfaction & 8.30 & 55.63 & 37.50 & 74.27 & 0.000 \\
\hline Direct Supervision Satisfaction & 38.00 & 47.63 & 50.00 & 62.68 & 0.034 \\
\hline Organization Satisfaction & 20.60 & 56.88 & 53.00 & 58.86 & 0.000 \\
\hline
\end{tabular}


Regarding the years of work in the department where the participants are currently working, the results showed the positive correlation with the normative commitment $(r=0.242, p=0.014)$, satisfaction from salary $(r=0.281, p<0.001)$ and from organization in general $(r=0.197, p=0.047)$, whereas there was a negative correlation with the satisfaction from the immediate superior $(r=$ $-0.198, p=0.046)$.

Regarding the total years of work, the results showed the negative correlation with physical fatigue $(r=-0.351, p<0.001)$, mental fatigue $(r=-0.238, p=$ $0.016)$ and total fatigue $(r=-0.320, p<0.001)$, positive correlation with affective commitment $(r=0.244, p=0.014)$, continuance $(r=0.265, p=0.007)$, normative commitment $(r=0.316, p<0.001)$ and overall commitment $(r=0.344, p<$ $0.001)$ as well as the positive correlation with job satisfaction $(r=0.278, p<$ $0.001)$, working conditions $(r=0.262, p=0.008)$ and satisfaction from the immediate supervisor $(r=0.229, p=0.021)$.

The results showed that factors such as age, holding or not a position of responsibility, education, marital status, staff specialization, working hours per week, the total working experience as well as the years of work in the department in which the employees are now occupied, have a statistically significant effect on fatigue, organizational commitment and job satisfaction.

\section{Discussion}

The purpose of this study was to investigate the effect of socio-demographic and occupational factors on the levels of fatigue, organizational commitment and job satisfaction in employees of pharmaceutical companies in the area of Athens. At first, it seems that a large number of employees in pharmaceutical companies exhibit fatigue. This finding is in full agreement with similar studies. In particular, in the study of Rahme et al. (2020), high scores of emotional, mental and physical fatigue in the workplace in a group of pharmacists were reported. Similarly, the study of Lan et al. (2020) demonstrated the high score of pharmacists' fatigue, stress and burnout.

In regard to the effect of socio-demographic factors on job satisfaction levels, the results of this study show that women have higher rates compared to men. This finding is consistent with the study of Carvajal and Popovici (2018), where women pharmacists showed a higher level of job satisfaction. One explanation for this result may be that women who are dissatisfied with their jobs may find it easier than men to change employers, work fewer hours, or leave the workforce to spend more time with their families. Another explanation may be that women sometimes have lower expectations than men for work and thus their goals are achieved more easily (Clark, 1997).

Those who were high school graduates had a higher score in terms of physical, mental and overall fatigue and show greater continuance commitment. Holders of a postgraduate or doctoral degree presented a higher score in terms of satisfaction with their salary, while bachelor graduates had higher satisfaction from 
the immediate supervisor. In contrast, there was no correlation between educational level and job satisfaction. In this respect, it could be said that employees with a lower level of education are more affected by the lack of job opportunities and are more likely to express higher levels of gratitude for the work they were able to secure and maintain. Knowledge of this relationship can be useful in designing more successful human resource strategies, such as hiring staff, job profiles, and training programs.

In addition, in the context of the assessment of marital status, divorced people exhibit greater physical fatigue, higher normative and total commitment, and a higher score of satisfaction from the immediate superior. Married or those with civil partnership showed a higher continuance commitment and greater satisfaction from the nature of work. Singles showed higher rates of total fatigue, while widowed indicated greater satisfaction with working conditions, salary and the organization. These findings reinforce the literature that highlights the impact of marital status and family support on employee fatigue (Fradelos et al., 2014; Pourmovahed \& Nasiriani, 2016).

Also, laboratory/research staff displayed higher rates of physical, mental and total fatigue. Senior executives showed the highest affective and overall commitment and highest satisfaction with working conditions, their promotion, the nature of work, the immediate supervisor and the organization in general. In addition, those who did not have a position of responsibility, showed higher levels of physical and overall fatigue, but also higher rates of affective and overall commitment, as well as satisfaction from both promotion and their immediate superior.

Based on the correlation analysis, the older the employees, the greater their continuance commitment and their satisfaction from the nature of the work and the immediate supervisor. Agreeing with the study of Carvajal and Popovici (2018) in which it was noted that older people were more satisfied with their work. This can be explained by the fact that older people have a growing awareness of the areas they practice their profession, from which they derive more satisfaction in the context of the working conditions of the organizations where they have worked for several years or enjoy privileges, such as more power, autonomy and professional prestige (Schroder, 2008). The results also showed that the longer the working hours per week, the lower the continuance commitment, as well as the satisfaction from the organization, thus harmonizing with the research of Estryn-Béhar and Van der Heijden (2012), which showed the negative effect of long working hours on the level of employee satisfaction.

The years of experience in the current department where the research participants now work had a positive relationship with the normative commitment and with satisfaction from the salary and the organization. However, the relationship with their supervisor was negatively associated. On the other hand, the total years of work had a positive relationship with continuance, normative and total commitment as well as with satisfaction from working conditions and from im- 
mediate supervisor. These findings can be explained by the fact that more experience contributes decisively to employees to appear more and more focused on their job tasks while increasing the level of satisfaction.

The preventive measures of the fatigue of the employees in the pharmaceutical companies must be carried out at organizational level, individual level and at the combination of these two. At the organizational level, new employees should be recruited taking into account the socio-demographic conditions for the execution of the specific tasks, new skills should be taught to the existing employees and the working conditions should always be into consideration for any improvements. At the individual level, employees need to learn relaxation skills in situations of increased stress in order to recognize and manage their mental state and to deal with unpleasant experiences. At the individual-organizational level, it is essential to seek the promotion of support from superiors and colleagues, the clarification of roles and the opportunities for development and promotion.

Last but not least, this study had some limitations due to its small sample. It is noted that the results can be further investigated in larger samples from other pharmaceuticals allowing future comparisons. In future research there may be the possibility of investigating other factors that are related to or affect the levels of fatigue, organizational commitment and job satisfaction.

\section{Conclusion}

The results indicated that factors such as age, holding or not a position of responsibility, education, marital status, staff specialization, working hours per week, the total working experience as well as the years of work in the department in which the employees are now occupied, have an impact on fatigue, organizational commitment and job satisfaction. In conclusion, it seems that there is an effect of various socio-demographic and work factors on the variables under investigation.

\section{Conflicts of Interest}

The authors declare no conflicts of interest regarding the publication of this paper.

\section{References}

Al Omar, A., Lolli, J., Chen-McCain, S. L., \& Dickerson, J. (2011). A Comparison between Full and Part-Time Lodging Employees on Job Satisfaction, Organizational Commitment, and Job Performance. Proceedings of the International CHRIE Conference-Refereed Track, Denver, 27-30 July 2011.

Ali, N., \& Kakakhel, S. J. (2013). Relationship between Occupational Stress and Organizational Commitment (Empirical Evidence from Pharmaceuticals Industry). Journal of Managerial Sciences, 7, 292-298.

Alikari, V., Fradelos, E., Sachlas, A., Panoutsopoulos, G., Lavdaniti, M., Palla, P., \& Zyga, S. (2016). Reliability and Validity of the Greek Version of "the Fatigue Assessment Scale". Archives of Hellenic Medicine, 33, 231-238. 
Allen, N. J., \& Meyer, J. P. (1990). The Measurement and Antecedents of Affective, Continuance and Normative Commitment to the Organization. Journal of Occupational Psychology, 63, 1-18. https://doi.org/10.1111/j.2044-8325.1990.tb00506.x

Anis, A., Khan, M. A., \& Humayoun, A. A. (2011). Impact of Organizational Commitment on Job Satisfaction and Employee Retention in Pharmaceutical Industry. African Journal of Business Management, 5, 7316-7324. https://doi.org/10.5897/AJBM10.1296

Ariapooran, S. (2014). Compassion Fatigue and Burnout in Iranian Nurses: The Role of Perceived social Support. Iranian Journal of Nursing and Midwifery Research, 19, 279284.

Bakker, A. B., Demerouti, E., \& Dollard, M. F. (2008). How Job Demands Affect Partners' Experience of Exhaustion: Integrating Work-Family Conflict and Crossover Theory. Journal of Applied Psychology, 93, 901-911. https://doi.org/10.1037/0021-9010.93.4.901

Barker, L. M., \& Nussbaum, M. A. (2011). Fatigue, Performance and the Work Environment: A Survey of Registered Nurses. Journal of Advanced Nursing, 67, 1370-1382. https://doi.org/10.1111/j.1365-2648.2010.05597.x

Buker, H., \& Dolu, O. (2010). Police Job Satisfaction in Turkey: Effects of Demographic, Organizational and Jurisdictional Factors. International Journal of Comparative and Applied Criminal Justice, 34, 25-51. https://doi.org/10.1080/01924036.2010.9678816

Carvajal, M. J., \& Popovici, I. (2018). Gender, Age, and Pharmacists' Job Satisfaction. Pharmacy Practice (Granada), 16, 1396. https://doi.org/10.18549/PharmPract.2018.04.1396

Clark, A. E. (1997). Job Satisfaction and Gender: Why Are Women So Happy at Work? Labour Economics, 4, 341-372. https://doi.org/10.1016/S0927-5371(97)00010-9

Clinebell, S. K., \& Clinebell, J. M. (2007). Differences between Part-Time and Full-Time Employees in the Financial Services Industry. Journal of Leadership \& Organizational Studies, 14, 157-167. https://doi.org/10.1177/1071791907308053

Cordes, C. L., \& Dougherty, T. W. (1993). A Review and an Integration of Research on Job Burnout. Academy of Management Review, 18, 621-656.

https://doi.org/10.5465/amr.1993.9402210153

Côté, J. N., Raymond, D., Mathieu, P. A., Feldman, A. G., \& Levin, M. F. (2005). Differences in Multi-Joint Kinematic Patterns of Repetitive Hammering in Healthy, Fatigued and Shoulder-Injured Individuals. Clinical Biomechanics, 20, 581-590.

https://doi.org/10.1016/j.clinbiomech.2005.02.012

Estryn-Béhar, M., \& Van der Heijden, B. I. (2012). Effects of Extended Work Shifts on Employee Fatigue, Health, Satisfaction, Work/Family Balance, and Patient Safety. Work, 41, 4283-4290. https://doi.org/10.3233/WOR-2012-0724-4283

Fagermoen, M. S. (1997). Professional Identity: Values Embedded in Meaningful Nursing Practice. Journal of Advanced Nursing, 25, 434-441.

https://doi.org/10.1046/j.1365-2648.1997.1997025434.x

Forrest, D. (1989). The Experience of Caring. Journal of Advanced Nursing, 14, 815-823. https://doi.org/10.1111/j.1365-2648.1989.tb01466.x

Fradelos, E., Mpelegrinos, S., Mparo, C., Vassilopoulou, C., Argyrou, P., Tsironi, M., \& Theofilou, P. (2014). Burnout Syndrome Impacts on Quality of Life in Nursing Professionals: The Contribution of Perceived Social Support. Progress in Health Sciences, 4, 102-109. https://doi.org/10.4081/hpr.2014.984

Fritschi, C., \& Quinn, L. (2010). Fatigue in Patients with Diabetes: A Review. Journal of Psychosomatic Research, 69, 33-41. https://doi.org/10.1016/j.jpsychores.2010.01.021 
Gawron, V. J., French, J., \& Funke, D. (2001). An Overview of Fatigue. In P. A. Hancock, \& P. A. Desmond (Eds.), Human Factors in Transportation. Stress, Workload, and Fatigue (p. 581-595). Mahwah, NJ: Lawrence Erlbaum Associates Publishers. https://doi.org/10.1201/b12791-3.9

Han, K., Trinkoff, A. M., \& Geiger-Brown, J. (2014). Factors Associated with Work-Related Fatigue and Recovery in Hospital Nurses Working 12-Hour Shifts. Workplace Health \& Safety, 62, 409-414. https://doi.org/10.3928/21650799-20140826-01

Harkin, M., \& Melby, V. (2014). Comparing Burnout in Emergency Nurses and Medical Nurses. Clinical Nursing Studies, 2, 152-163. https://doi.org/10.5430/cns.v2n3p152

Huysmans, M. A., Hoozemans, M. J., van der Beek, A. J., de Looze, M. P., \& van Dieen, J. H. (2010). Position Sense Acuity of the Upper Extremity and Tracking Performance in Subjects with Non-Specific Neck and Upper Extremity Pain and Healthy Controls. Journal of Rehabilitation Medicine, 42, 876-883. https://doi.org/10.2340/16501977-0585

Ilies, R., Huth, M., Ryan, A. M., \& Dimotakis, N. (2015). Explaining the Links between Workload, distress, and Work-Family Conflict among School Employees: Physical, Cognitive, and Emotional Fatigue. Journal of Educational Psychology, 107, 1136. https://doi.org/10.1037/edu0000029

Koustelios, A. D., \& Bagiatis, K. (1997). The Employee Satisfaction Inventory (ESI): Development of a Scale to Measure Satisfaction of Greek Employees. Educational and Psychological Measurement, 57, 469-476. https://doi.org/10.1177/0013164497057003008

Koustelios, A., \& Kousteliou, I. (1998). Relations among Measures of Job Satisfaction, Role Conflict, and Role Ambiguity for a Sample of Greek Teachers. Psychological Reports, 82, 131-136. https://doi.org/10.2466/pr0.1998.82.1.131

Lan, Y. L., Huang, W. T., Kao, C. L., \& Wang, H. J. (2020). The Relationship between Organizational Climate, Job Stress, Workplace Burnout, and Retention of Pharmacists. Journal of Occupational Health, 62, e12079. https://doi.org/10.1002/1348-9585.12079

Marchese, M. C., \& Ryan, J. (2001). Capitalizing on the Benefits of Utilizing Part-Time Employees through Job Autonomy. Journal of Business and Psychology, 15, 549-560. https://doi.org/10.1023/A:1007814816178

Maslach, C., Schaufeli, W. B., \& Leiter, M. P. (2001). Job Burnout. Annual Review of Psychology, 52, 397-422. https://doi.org/10.1146/annurev.psych.52.1.397

McGinnis, S. K., \& Morrow, P. C. (1990). Job Attitudes among Full- and Part-Time Employees. Journal of Vocational Behavior, 36, 82-96. https://doi.org/10.1016/0001-8791(90)90016-U

Meijman, T. F. (1997). Psychische vermoeidheid [Mental Fatigue]. Vermoeidheid [Fatigue]. Cahiers Bio-Wetenschappen en Maatschappij, 19e jrg. nr3 (pp. 5-15). Rotterdam: Stichting Bio-Wetenschappen en Maatschappij.

Meyer, J. P., Allen, N. J., \& Smith, C. A. (1993). Commitment to Organizations and Occupations: Extension and Test of a Three-Component Conceptualization. Journal of Applied Psychology, 78, 538. https://doi.org/10.1037/0021-9010.78.4.538

Michielsen, H. J., De Vries, J., \& Van Heck, G. L. (2003). Psychometric Qualities of a Brief Self-Rated Fatigue Measure: The Fatigue Assessment Scale. Journal of Psychosomatic Research, 54, 345-352. https://doi.org/10.1016/S0022-3999(02)00392-6

Michielsen, H. J., De Vries, J., Van Heck, G. L., Van de Vijver, F. J., \& Sijtsma, K. (2004). Examination of the Dimensionality of Fatigue. European Journal of Psychological As sessment, 20, 39-48. https://doi.org/10.1027/1015-5759.20.1.39 
Oh, M. O., Sung, M. H., \& Kim, Y. W. (2011). Job Stress, Fatigue, Job Satisfaction and Commitment to Organization in Emergency Department Nurses. Journal of Korean Clinical Nursing Research, 17, 215-227.

Pourmovahed, Z., \& Nasiriani, K. (2016). Perception of Fatigue in Female Nurses Employed in Hospitals. Women Health Open Journal, 3, 1-7. https://doi.org/10.17140/WHOJ-3-115

Rahme, D., Lahoud, N., Sacre, H., Akel, M., Hallit, S., \& Salameh, P. (2020). Work Fatigue among Lebanese Community Pharmacists: Prevalence and Correlates. Pharmacy Practice, 18, 1844. https://doi.org/10.18549/PharmPract.2020.2.1844

Sarminah, S. (2006). The Contribution of Demographic Variables: Job Characteristics and Job Satisfaction on Turnover Intentions. Journal of International Management Studies, $1,2-12$.

Schroder, S. (2008). Job Satisfaction of Employees at a Christian University. Journal of Research on Cristian Education, 17, 225-246. https://doi.org/10.1080/10656210802433467

Stokes, A. F., \& Kite, K. (2017). Flight Stress: Stress, Fatigue and Performance in Aviation. London: Routledge. https://doi.org/10.4324/9781315255200

Tang, C., Liu, C., Fang, P., Xiang, Y., \& Min, R. (2019). Work-Related Accumulated Fatigue among Doctors in Tertiary Hospitals: A Cross-Sectional Survey in Six Provinces of China. International Journal of Environmental Research and Public Health, 16, 3049. https://doi.org/10.3390/ijerph16173049

Thorsteinson, T. J. (2003). Job Attitudes of Part-Time vs. Full-Time Workers: A Meta-Analytic Review. Journal of Occupational and Organizational Psychology, 76, 151177. https://doi.org/10.1348/096317903765913687

Woodhead, E. L., Northrop, L., \& Edelstein, B. (2016). Stress, Social Support, and Burnout among Long-Term Care Nursing Staff. Journal of Applied Gerontology, 35, 84105. https://doi.org/10.1177/0733464814542465

Zyga, S., Alikari, V., Sachlas, A., Fradelos, E., Stathoulis, J., Panoutsopoulos, G., Georgopoulou, M., Theophilou, P., \& Lavdaniti, M. (2015). Assessment of Fatigue in End Stage Renal Disease Patients Undergoing Hemodialysis: Prevalence and Associated Factors. Medical Archives, 69, 376-380. https://doi.org/10.5455/medarh.2015.69.376-380 